\title{
Expression of Aprotinin in anthers causes male sterility in tobacco var Petit havana
}

\author{
Arun Viswanathan ${ }^{a^{*}}$. Boney Kuriakose ${ }^{b}$. Shantharam Bharadwaj ${ }^{c}$. George Thomas ${ }^{d}$ \\ * - Corresponding author: Tel- 91-44-45928602, Fax - 91-44-24767008, E-mail \\ arunphd@gmail.com \\ a \& b - CAS in Botany, University of Madras, Guindy, Chennai, India-600025. \\ Current address of authors: \\ a - Department of Biotechnology, FBMSTR, Sri Ramachandra University, Porur, Chennai, India - \\ 600116. \\ b - Department of Plant Sciences - Forest and Agricultural Biotechnology Institute, University of \\ Pretoria, South Africa. \\ c - Wake Forest Institute of Regenerative Medicine, Winston, Salem, NC -27157. \\ d - Interfield Laboratories, Cochin, India - 682005.
}




\section{Abstract}

Expression of many proteinases has been documented during anther development. Although their roles are not completely understood, their inhibition could possibly result in impairment of anther development leading to male sterility. We proposed that such an impairment of anther development can be engineered in plants and explored for hybrid seed production. Here we report that anther specific expression of Aprotinin gene (serine proteinase inhibitor) in tobacco has resulted in male sterility. Southern analysis of the transgenic plants revealed the integration of Aprotinin gene and zymogram analysis confirmed the expression of APROTININ in the anthers of the transgenic plants. Transverse sections of anthers of transgenic male sterile plants showed damage to the tapetum, the site of tissue-specific expression of the TA29 promoter. The pollen germination in the transgenic plants ranged between $2 \%$ to $65 \%$ that confirmed the impairment in pollen production leading to male sterility and low seed yield. Thus inhibition of serine proteinases that are expressed during anther development resulted in impaired pollen production and male sterility though more work is required to elucidate the exact role of these proteinases.

Key words Aprotinin. Male sterility. Hybrid seeds. Proteinase inhibitor. Anther development. Pollen production.

\section{Abbreviations}

PCD Programmed cell death

PCR Polymerase chain reaction

DNA Deoxyribonucleic acid

SDS Sodium Dodecyl Sulphate

PAGE Polyacrylamide gel electrophoresis

\section{Introduction}

Another development is a dynamic process that involves many events that are precisely coordinated and culminates in dehiscence of mature anther to release pollen. Even a minor aberration in these temporally and spatially regulated processes would result in male sterility. Proteolytic enzymes play a central role in homeostasis and developmental processes in plants. As part of Ubiquitin/ proteosome machinery, proteinases play a central role in many key aspects of plant physiology, growth and defense. They have also been reported to respond to hormone signaling (auxin, jasmonic acid, ABA, etc.,) (Vierstra 2003; Schaller 2004). Tissue-specific expression of some proteinases (aspartic and serine classes) suggests that they have a specific 
role in development of anthers (Taylor et al. 1997; Jorda et al. 1999; Meichtry et al. 1999; DeGuzman and Riggs 2000; Parish and Liu 2010).

During taptal development many genes that code for transcription factors [e.g. SPOROCYTLESS/NOZZLE (SPL/NZZ), DYSFUNCTIONAL TAPETUM1 (DYT1)]; leucine-rich repeat receptor-like kinases [e.g. EXCESS MICROSPOROCYTES1/EXTRA SPOROGENOUS CELLS (EMS1/EXS)] have been reported recently (Parish and Liu 2010; Zhang et al. 2006; Lee et al. 2004; Schiefthaler et al. 1999; Yang et al. 1999; Zhang et al. 2007; Zhao et al. 2002]. Many proteins like proteinases, proteasome and 5B-CRP protein were upregulated in tomato anthers suggesting their possible role in PCD of anthers during development. Some of the proteinase genes that were expressed during another development include aspartic proteinase (PCS1 gene from Arabidopsis), cysteine proteinase (OsCP1 from rice) and serine proteinase (LIM9 from Lilium, PrCM-3 from Pinus) (Taylor et al. 1998; McNeil KJ and Smith AG 2005; Walden et al. 1999; Parish and Liu 2010).

During late anther development, in most plants, one or more cell types or layer/s of cells are destroyed by programmed cell death (PCD), a process that is coordinated with microsporocyte development and pollen dispersal (Goldberg et al. 1993). Proteolytic activities increase as anther development progresses and these have been temporally correlated with apoptotic events, which precede dehiscence, as well as with events leading to the maturation of viable pollen. PCD of tapetum, circular cell clusters and other cell layers is critical for proper pollen release that involves mitochondria and caspases (Wang et al. 1999; Balk and Leaver 2001). Tapetal degradation is very essential for the developing pollen to obtain the nutrition it requies (Parish and Liu 2010). When the timing of tapetum degeneration was delayed by tapetum-specific expression of a gene, AtBI-1 at the tetrad stage, it resulted in pollen abortion (Kawanabe et al. 2006). Recently a gene, tapetum degeneration retardation (TDR), has been shown to regulate tapetal PCD by altering aliphatic metabolism and gene regulation during pollen development (Zhang et al. 2008; Li et al. 2006). A gene (TDF-A5, transcript-derived fragment) coding for $26 S$ protease regulatory particle non-ATPase subunit 5 has been identified that might have a potential role in PCD regulation in pollens of S-type cytoplasm of male sterile maize plants (Zhang and Zheng 2008). Since the PCD in plants uses many types of caspases-like preoteinases or caspases-unrelated proteinases, their substrates are also varied, though the exact role of these proteinases has to be elucidated (Woltering et al., 2010; Parish and Liu 2010). Hence, temporal regulation of PCD is essential for microsporogenesis and PCD of tapetum begins at the tetrad stage (Kawanabe et al. 2006; Parish and Liu 2010).

By breaking down tissues and proteins, the proteinases play an important role in sculpting exquisite pollen wall patterns that is critical for pollination (DeGuzman and Riggs 2000). It has been demonstrated in Brassica napus pollen that some of the major proteins are derived from precursor proteins (Murphy and Ross 1998). In maize, proteinase activity has been 
observed during pollen development (Taylor et al. 1997), similarly in Lilium, the serine proteinase LIM9 is secreted into anther locules (Radlowski et al. 1996). Recently a gene, OsSIZ1, a small ubiquitin-related modifier (SUMO) E3 ligase that helps in anchoring SUMO to protein substrates for modifications has been shown to be developmentally regulated in rice reproductive tissues (Wang et al. 2010). Since improper anchoring of SUMO to protein substrates will result in impaired processing of target proteins and thereby development will be affected. During meiotic purging, where RNA, ribosomes and protein turnover takes place, proteinases have been proposed to play an important role (DeGuzman and Riggs 2000).

ESTs analysis of chrysanthemum inflorescence has shown the expression of many genes that are involved in protein turnover and pathways like flavonoid, carotenoid, etc (Chen et al. 2010). Most of these genes like glucanase are spatially and temporally regulated during anther development. Similar genes like barnase and genes involved in the flavonoid pathway have been used to engineer male sterility in plants (Mariani et al. 1990; Mariani et al. 1992; Worrall et al. 1992; Derksen et al. 1999). When these genes are over-expressed or suppressed in anther cells, they cause male sterility by disrupting the harmony of events during anther development. Some of the genes act by modifying molecules or metabolites like RNA (barnase RNAse from Bacillus), auxins, sugars, etc and cause male sterility (Perez-Prat and Campagne 2002).

Since serine proteinases have been shown to be expressed during anther development (DeGuzman and Riggs 2000), we hypothesized that their knock-down would result in impaired anther development and male sterility. One of the strategies would be to express a proteinase inhibitor, such as APROTININ in anthers that would inhibit the serine proteinases leading to anomalies in another development. APROTININ has been shown to inhibit serine proteinases that belong to the trypsin family but not those belonging to subtilase family (Reeck et al. 1997). We had earlier shown that expression of Aprotinin gene under a constitutive promoter CaMV35S in transgenic tobacco conferred insect resistance. The constitutive expression of APROTININ in these transgenic plants had no deleterious effects (i.e) these plants were fertile and had normal morphology (Bharadwaj 1999). The insect resistance of these transgenic plants was due to inhibition of the serine proteinases produced in the gut of insects by the APROTININ resulting in mortality (Josephrajkumar et al. 2006). We used this Aprotinin gene as its codons were optimized for expression in dicots and its successful demonstration of its activity against serine proteinases of insects.

\section{Materials and methods}

\section{Bacterial culture and maintenance}

E. coli DH5a' and Agrobacterium LBA4404 were used in the current study. E. coli was grown on Luria-Bertani (LB) medium and transformed using Hanahan method (Sambrook et al., 
1989). Agrobacterium was maintained on Agrobacterium (AB) minimal medium with Rifampicin 5 $\mu \mathrm{g} / \mathrm{ml}$ for selection and transformed by triparental mating method (Ditta et al. 1980). The transformed bacteria were selected on LB and AB media amended with Chloramphenicol (25 $\mu \mathrm{g}$ /ml).

\section{Plant material and growth}

Tobacco var Petit havana leaf discs were transformed by Agrobacterium mediated transformation method (Horsch et al. 1985). Briefly, the medium used for co-culture and regeneration contained Murashige and Skoog (MS) basal salts amended with Benzylaminopurine (BAP - $1 \mu \mathrm{g} / \mathrm{ml}$ ) and Naphthalene acetic acid (NAA - $0.1 \mu \mathrm{g} / \mathrm{ml}$ ) for callus induction and half strength MS basal medium without hormones was used for seed initiations, rooting and micropropagation of plants. The transformed plants were selected on medium containing $40 \mu \mathrm{g}$ /ml Hygromycin and subsequently grown in the green-house. The inflorescence of the transgenic plants was bagged to prevent cross-pollination and seeds were collected.

\section{Constructs used for tobacco transformation}

The well-characterized TA29 promoter (Accession number no $\underline{\mathbf{X 5 2 2 8 3}}$ ), active in tapetum of tobacco was chosen for anther specific expression of Aprotinin gene in this study. The functionality of the TA29 promoter was tested using Gus gene in our lab (data not shown). Two constructs (p1229n and pTA) (Fig. 1a, 1b, respectively) used in the present study were derived from pCAMBIA1200 obtained from Dr. Richard Jefferson, CAMBIA, Australia. The p1229n construct served as transformation (vector) control and had TA29 promoter, multiple cloning sites (MCS) and NOS terminator (Fig. 1a). The Aprotinin gene was sub-cloned from another plasmid pSB301 that was constructed and used by Bharadwaj (1999). The Aprotinin gene was a synthetic gene that had codons optimized for expression in dicot plants. This Aprotinin gene was released as a BamH1 and Sac1 fragment from pSB301 and cloned into p1229n plasmid and renamed as pTA. The clones obtained were sequenced prior to mobilization into Agrobacterium. The constructs were mobilized to Agrobacterium LBA4404 by the tri-parental mating method (Ditta et al. 1980); transformants were confirmed by PCR and then used to transform tobacco leaf discs. Putative transgenic $\mathrm{T}_{0}$ plants carrying the Aprotinin gene were labeled as TA1, TA2, so on and plants carrying $\mathrm{p} 1229 \mathrm{n}$ were labeled as $1229 \mathrm{n} 1,1229 \mathrm{n} 2$ etc.

\section{Southern analysis}


Genomic DNA was isolated from the plants using the SDS method (Dellaporta et al. 1983). PCR was carried out to check presence of transgene in the putative transgenic plants using gene specific primers. Southern analysis was done to confirm integration of the transgene (Aprotinin), briefly $20 \mu \mathrm{g}$ of genomic DNA was digested with Hindlll (100U) restriction enzyme. The digested DNA were separated on $1 \%$ agarose gel and transferred onto Hybond $\mathrm{N}^{+}$nylon membrane by alkaline transfer (Sambrook et al. 1989). The nylon membrane carrying digested DNA was then probed with a radio-labeled 850 bp fragment obtained by digesting pTA with HindIII. The radio-labeled probe (850 bp fragment) consisted of Aprotinin gene and TA29 promoter. Hybridization was carried out at $56^{\circ} \mathrm{C}$ overnight and washes were carried out at $56^{\circ} \mathrm{C}$ with 3 X SSC and 1 X SSC along with $0.1 \%$ SDS for 15 minutes each. The membrane was then exposed to $\mathrm{X}$-ray film for 4 days at $-70^{\circ} \mathrm{C}$ and developed.

\section{Protein isolation and zymogram analysis}

Total protein was isolated from $100 \mathrm{mg}$ of Stage 2 anthers (Koltunow et al. 1990) of tobacco plants using NRD buffer $\{20 \mathrm{mM}$ Tris $(\mathrm{pH} 8.6), 10 \%$ glycerol, $1 \%$ SDS $\}$ (Taylor et al. 1997; DeGuzman and Riggs 2000). The isolated proteins were quantified using a method by Lowry et al. (1951). $20 \mu \mathrm{g}$ of total protein (not boiled) was separated on 12\% SDS-PAGE with $0.15 \%$ gelatin at $4^{\circ} \mathrm{C}$ for $4-5$ hours. The gel was incubated in $2.5 \%$ Triton $\mathrm{X}-100$ at room temperature for $30 \mathrm{~min}$ and washed thrice with water. The gel was incubated in activation buffer [(1\% Triton X-100, $50 \mathrm{mM}$ HEPES, $5 \mathrm{mM}$ L-Cysteine $(\mathrm{pH} 8)]$ overnight at room temperature to observe proteinase activity. The gel was then rinsed twice with water, followed by fixing in solution consisting of $25 \%$ methanol and $9 \%$ acetic acid for $15 \mathrm{~min}$ and stained with Coomassie Brilliant Blue in fixer and washed. The proteinase activity was observed as clear zones in a blue background (Michaud et al. 1993; Taylor et al. 1997).

\section{Anther morphology and pollen germination analysis}

Stage 2 anthers (Koltunow et al. 1990) of tobacco were used for paraffin embedded microtome sectioning. The $10 \mu \mathrm{m}$ transverse sections were stained with Toluidine blue $(0.05 \%)$ and morphological features were observed. To study pollen germination 3 semi-sterile $T_{1}$ plants (TA2-5, TA12-2 and TA31-9), 2 sterile $T_{0}$ plants (TA4 and TA20), 1 untransformed Petit havana and 1 transgenic $T_{0}$ plant (1299n10, vector control) were used. Pollen was collected from just dehisced anthers of a single flower into $200 \mu \mathrm{l}$ of pollen germination medium that was modified [Sucrose - 15\%, $\mathrm{Ca}\left(\mathrm{NO}_{3}\right)_{2}-0.03 \%$, Boric acid $(\mathrm{pH} 7)-0.01 \%$ ] (Sridhar 2001). The pollen were incubated at $25^{\circ} \mathrm{C}$ for 4 hours in the dark and then $25 \mu \mathrm{l}$ of the suspension was mounted onto a custom-made glass slide with 64 grids of $2 \mathrm{~mm} \times 2 \mathrm{~mm}$ dimension. The pollen with and without 
germination were counted and documented using a light microscope. Three replicates per plant were used to calculate the percentage of pollen germination.

\section{Results and discussion}

\section{Molecular analysis of transformed tobacco}

About 20 independent transformed tobacco $\left(T_{0}\right)$ lines were obtained for each of the constructs and were subjected to PCR and Southern analyses. Most of the putative transgenic plants were positive for the presence of transgene when PCR was done with gene specific primers (data not shown). About 10 putative transgenic plants carrying p1229n construct and 16 putative transgenic plants carrying pTA construct were hardened and grown in a green-house. All the putative transgenic plants carrying p1229n construct had a normal morphology and were fertile. Southern analysis was done for 10 lines of tobacco plants that carried the pTA construct. The genomic DNA was digested with HindIII restriction enzyme that would result in release of Aprotinin gene along with TA29 promoter (850 bp band) (Fig. 1). The blot obtained was probed with 850 bp fragment (TA29 promoter and Aprotinin gene) obtained by digestion of plasmid pTA with HindIII enzyme. All except three plants (TA-3, TA-18 and TA-22) had the expected fragment of $850 \mathrm{bp}$ that confirmed the integration of Aprotinin gene along with promoter in those plants. Another larger fragment was also observed in the plants (transformed and untransformed tobacco) (Fig. 1) corresponding to native TA29 promoter. Since the Aprotinin gene was driven by TA29 promoter that is expressed spatially and temporally in the tapetum of anthers, large number of Stage 2 anthers has to be obtained to isolate mRNA or protein to study northern or western analyses. Since tapetum is an ephemeral layer consisting of few cells, it is difficult to collect large number of Stage 2 anthers and hence northern analysis was not attempted. Perhaps technologies like laser dissection microscopy or in situ hybridization could be attempted to isolate tapteum layer alone to isolate protein or RNA and analyze them (Emmert-Buck et al. 1996; Kerk et al. 2003).

\section{Floral morphology and pollen germination analysis}

The transgenic plants classified into fertile (normal pollen count and pollen germination percentage), semi-sterile (low pollen count and pollen germination percentage) and sterile plants (very low pollen count and pollen germination percentage). Of the 16 transgenic plants that carried pTA construct, 8 were either sterile or semi-sterile and the remaining were fertile and produced viable seeds. The three plants (TA3, TA18 and TA22) that were negative in Southern analysis were fertile (Fig. 1). Of the 8 plants that were showing signs of male sterility 5 were semisterile (TA1, TA2, TA12, TA19 and TA31) and 3 were sterile (TA4, TA10 and TA20). The male 
sterile plants had normal plant morphology and grew normally except for severe reduction in pollen production and pollen germination (data not shown).

Transverse section of anther of one semi-sterile plant (TA12, $\mathrm{T}_{1}$ plant) showed that the tapetum was impaired along with reduction in pollen mass as compared to control plant (Fig. 2).. The rest of the anther remained intact without any aberrations; this confirmed that expression of the APROTININ in the anthers did not have any deleterious effect on the other cells of anther except tapetum and pollen production (Fig. 2). The transgenic plants that carried p1229n construct also had a normal morphology and produced viable pollen and seeds (data not shown). The semi-sterile plants produced less pollen and did not produce viable seeds by self-pollination (Fig. 3a \& 3b, TA12; Table 1) when compared with control plants. These plants produced viable seeds when manually cross-pollinated with pollen from untransformed plants. The semi-sterile plants did produced seeds when cross-pollinated with their own pollen but had varied viability. The sterile plants produced little pollen that was mostly non-viable (TA 4, Fig. 3a \& 3b; Table 1). These plants produced viable seeds when manually cross-pollinated with pollen from untransformed plant indicating the potential usefulness of these plants in the production of hybrid seeds.

Pollen was collected and germination percentage was calculated from flowers of five transgenic plants that showed signs of sterility, a plant that carried p1229n (vector control, 1229n10) and an untransformed plant (Fig. 4a). The percentage of pollen germination in untransformed and transgenic plant, 1229n10 (vector control) was $85 \%$ and $88 \%$ respectively, while that of transgenic plants that carried Aprotinin gene ranged from $2 \%$ to $65 \%$ (Fig. $4 \mathrm{~b}$, Table 1). The transgenic TA31-9 showed the highest pollen germination percentage (65\%) among the plants that expressed APROTININ, whereas the plants TA4 and TA20 showed the lowest percentage ( $2 \%$ and $9 \%$ respectively). The pollen germination percentage of untransformed and transgenic plant carrying $\mathrm{p} 1229 \mathrm{n}$ were comparable, this showed that the pollen production and germination was not affected by the transformation methodology used in the current study. The semi-sterile transgenic plants used for pollen germination study were $T_{1}$ plants which showed that the Aprotinin gene was stably functioning in next generation plants (i.e) the trasngene is functional. The reduction in pollen production (Table 1) in transgenic plants carrying Aprotinin gene correlated with reduction in pollen germination and seed production.

The aberrations in floral tissues like pollen production, germination (Table 1) or pollen dehiscence (absence of self-pollination) observed in the transgenic plants expressing the Aprotinin gene could be due to unavailability or improper processing of the precursor proteins required for pollen production during anther development. In Brassica napus the proteins deposited on pollen has been shown to be obtained from precursor proteins during pollen development (Murphy and Ross 1998). Serine proteinases have been proposed to play a major role in protein turnover during many developmental stages in organisms (Reeck et al. 1997). Few 
serine proteinases like LIM9 (subtilisin like-serine proteinase from Lilium), PrMC-3 (serine hyrdolase form Pinus) have been reported to be expressed during microsporogenesis (Taylor et al. 1998; McNeil KJ and Smith AG 2005; Walden et al. 1999; Parish and Liu 2010). Hence any changes in the protein turnover or homeostasis due to mistiming or impairment of serine proteinases during anther development could impact pollen production as observed in this study.

Yet another possibility for the observed dysfunction in this study could be due to a temporal disturbance in PCD during anther development, as evidenced by pollen abortion observed in plants that had delayed PCD in anthers (Kawanabe et al. 2006). Also many cell types like circular cell clusters, tapetum, etc undergo PCD prior to anther dehiscence and have been proposed to be essential for normal pollen dispersal (Parish and Liu 2010). The knockout of TDR gene in rice $t d r$ mutants had resulted in male sterile plants and the $t d r$ microarray analysis identified many genes that were regulated by TDR. The gene TDR has been proposed to act as a major regulator of tapetal PCD by modifying aliphatic metabolism and also by regulating genes involved in PCD like caspases, protein turnover, calcium metabolism, etc during anther development (Zhang et al. 2008). Disturbance in tapetal PCD like mistiming has been shown to result in male sterility in case of some of the cytoplasmic male sterile plants observed in nature (Parish and Liu 2010).

\section{Zymogram analysis of male sterile plants}

Total protein was isolated from anthers $(100 \mathrm{mg})$ of vector control $\mathrm{T}_{0}(1229 \mathrm{n} 6), 3$ semisterile $T_{1}$ plants (TA2-5, TA12-2 and TA31-9) and 2 sterile $T_{0}$ plants (TA4 and TA20). Zymogram analysis was carried out with trypsin (10 ng and $20 \mathrm{ng}$ ) as internal control (Fig. 5) and it was observed that atleast three serine proteinases of varying molecular weights were present in the anthers of tobacco as seen in control plant (1229n6; Fig. 5, Lane 3). Of these, one serine proteinase was similar in molecular weight to that of trypsin (Fig. 5, Lanes 3-8). This was the first demonstration of presence of serine proteinases in anthers of tobacco. In the transgenic plants carrying Aprotinin gene (Fig. 5, Lanes 4-8), proteinase activity was severely reduced when compared to control plant (1229n6; Fig. 5, Lane 3). The higher molecular weight serine proteinase was completely inhibited in TA4 (Fig. 5, Lane 5), while very mild activity was observed in the other plants (Fig. 5, Lanes 5-8). The medium molecular weight serine proteinase was completely inhibited in all the transgenic plants whereas in case of the smaller serine proteinase very low to mild activity was observed (Fig. 5, Lanes 4-8). The absence of proteolytic activity (clear zones) in lanes 4-8 carrying protein from transgenic plants carrying Aprotinin gene confirmed that the inhibition was due to APROTININ, that in turn suggested that the male sterility observed in these plants was due to inhibition (partial or complete) of the serine proteinases. The presence of active serine proteinases in the transgenic plant carrying p1229n constructs $(1229 n 6$; 
Fig. 5, Lane 3) confirmed that transformation procedure employed had no deleterious effect on transgenic plants as evidenced by production of functional pollen and seed in all the transgenic plants carrying p1229n construct (TA29 promoter, multiple cloning site and NOS terminator) (Fig. 4 \& Fig. 5).

The expression of serine proteinases LIM9 in Lilium anthers has been proposed to play an important role in anther development, as many cell types undergo programmed cell death during this stage (Taylor et al. 1997; Meichtry et al. 1999; DeGuzman and Riggs 2000). Recently two cysteine proteinases were found to be up-regulated in rice $t d r$ mutants that were male sterile (Zhang et al. 2008). Thirteen genes involved in post-translational modifications, protein turnover and chaperonins were also shown to be regulated in tdr mutants (10 up-regulated and 3 downregulated) (Zhang et al. 2008). Recently, the gene PROMOTION OF CELL SURVIVAL 1 (PCS1) from Arabidopsis was identified as an aspartic proteinase. The function of this gene has been demonstrated in pcs1 mutants where the male and female gametophytes were degenerated and when expressed ectopically it resulted in male sterility by preventing PCD of septum and stomium cells ( $\mathrm{Ge}$ et al. 2005). The mistimed expression or the inhibition of proteinases in anthers has been shown to result in male sterility, which confirms that these proteins play a major role in anther development, though the exact role of each of them needs to be elucidated (Parish and Liu 2010).

We report for the first time, that expression of a serine proteinase inhibitor (APROTININ) in anthers of tobacco plants resulted in inhibition of serine proteinases thereby causing male sterility. Although further work to elucidate the exact role of each of the serine proteinases observed in the anthers is required, we propose that these serine proteinases play a critical role in pollen production, pollen germination and probably pollen dispersal.

In summary, previous studies that demonstrated engineered male sterility has used genes that affect RNA metabolism (barnase), carbohydrate metaboliosm (glucanase) or jasmonate metabolism, etc (Mariani et al. 1990; Mariani et al. 1992; Worrall et al. 1992; PerezPrat and Campagne 2002). Some of these genes like barnase, glucanase when expressed constitutively might affect the transformed plants severely whereas ectopic expression of Aprotinin gene has been shown to confer insect resistance in transgenic tobacco (Bharadwaj 1999; Josephrajkumar et al. 2006). Hence it would be advantageous to express Aprotinin in both constitutive and anther specific manner as it would result in a transgenic plant that would have insect resistance and also male sterile (hybrid seed production). Recently two cysteine proteinases (BoCysP1 and $B O C P 3$ ) from Brassica have been shown to cause male sterility when expressed in anthers of Arabidopsis thaliana (Konagaya et al. 2008). Similarly when the expression of PCS1 gene (aspartic proteinase) was altered or modified in Arabidopsis thaliana it has led to male sterility (Ge et al. 2005). The intact inhibitory activity of APROTININ in the transgenic (semi-sterile and sterile) tobacco plants as demonstrated by zymogram and the 
impaired pollen and seed production implied the importance of these serine proteinases in anther development (Fig. 2-5, Table 1). Although TA29 has been shown to be useful in this study, other anther specific promoters like A3, A6 and A9 (Brassica); OSACE1, OSCER1, OSMSP (rice); ORF238 (wheat) that are expressed at early stages of anthesis could also be utilized (Scott et al. 1991a; Scott et al. 1991b; Hird et al. 1993; Aarts et al. 1997; Glover et al. 1998; Sanders et al. 1999; Konagaya et al. 2008; Kato et al. 2010; Jiang et al. 2009; El-Shehawi et al. 2010). Thus we have shown that when expression of serine proteinases during anther development was altered or hindered it could result in male sterility (engineered) with a possible application in hybrid seed production.

\section{Acknowledgements}

Author AV and BK thank Council for Scientific and Industrial Research for the research fellowship. Valuable suggestions of Prof. T. S. Lokeswari and Dr. K. K. Kumar during the course of the work and in manuscript preparation are acknowledged. The authors gratefully acknowledge the timely help from Dr. Samuel S. Gnanamanickam, Dr. N. Anand and Dr. Ajay Parida in providing lab facilities as well as green-house for part of the work.

\section{References}

Aarts MG, Hodge R, Kalantidis K, Florack D, Wilson ZA, Mulligan BJ, Stiekema WJ, Scott R, Pereira A (1997) The Arabidopsis MALE STERILITY 2 protein shares similarity with reductases in elongation/condensation complexes. Plant J. 12: 615-623

Balk J, Leaver CJ (2001) The PET1-CMS mitochondrial mutation in sunflower is associated with premature programmed cell death and cytochrome c release. Plant Cell 13: 1803-1818

Bharadwaj S (1999) Engineering of bovine pancreatic trypsin inhibitor gene for plant expression.

Ph.D. Dissertation, University of Madras, Chennai.

Chen S, Miao H, Chen F, Jiang B, Lu J, Fang W (2009) Analysis of expressed sequenced tags (ESTs) collected from the inflorescence of chrysanthemum. Plant Mol Biol Rep 27: 503510.

DeGuzman R, Riggs CD (2000) A survey of proteinases active during meiotic development. Planta 210: 921-924

Dellaporta SL, Wood J, Hicks JB (1983) A plant DNA minipreparation: version II. Plant Mol. Biol. Reptr. 1: 19-21

Derksen J, van Wezel R, Knuiman B, Ylstra B, van Tunen AJ (1999) Pollen tubes of flavonoldefecient Petunia show striking alterations in wall structure leading to tube disruption. Planta 207: 575-581

Ditta G, Stanfield S, Corbin D, Helinski DR (1980) Broad host range DNA cloning system for Gram-negative bacteria: construction of a gene bank of Rhizobium meliloti. Proc. Natl. Acad. Sci. U.S.A. 77:7347-7351 
El-Shehawi AM, Elseehy MM, Hedgecoth C (2010) Isolation and sequence analysis of wheat tissue-specific cDNAs by differential display. Plant Mol Biol Rep DOI 10.1007/s11105-0100213-1

Emmert-Buck MR, Bonner RF, Smith PD, Chuaqui RF, Zhuang Z, Goldstein SR, Weiss RA, Liotta LA (1996) Laser capture microdissection. Science 274:998-1001

Ge X, Dietrich C, Matsuno M, Li G, Berg H, Xia Y (2005) An Arabidopsis aspartic protease functions as an anti-cell-death component in reproduction and embryogenesis. EMBO Rep. 6: $282-288$

Glover J, Grelon M, Craig S, Chaudhury A, Dennis E (1998) Cloning and characterization of MS5 from Arabidopsis: a gene critical in male meiosis. Plant J. 15: 345-356

Goldberg RB, Beals TP, Sanders PM (1993) Anther development: Basic principles and practical applications. Plant Cell 5: 1217-1229

Hird DL, Worrall D, Hodge R, Smartt S, Paul W, Scott R (1993) The anther-specific protein encoded by the Brassica napus and Arabidopsis thaliana $A 6$ gene displays similarity to $b-1$, 3-glucanases. Plant J. 4: 1023-1033

Horsch RB, Fry JE, Hoffman NL, Eichholtz D, Rogers SG, Fraley RT (1985) A simple and general method for transferring genes into plants. Science 227: 1229-1231

Jorda L, Coego A, Conejero V, Vera P (1999) A genomic cluster containing four differentially regulated subtilisin-like processing proteinase genes in tomato plants. J. Biol. Chem. 274: 2360-2365

Josephrajkumar J, Chakrabarty R, Thomas G (2006) Midgut proteases of the cardamom shoot and capsule borer Conogethes punctiferalis (Lepidoptera: Pyralidae) and their interaction with aprotinin. Bulletin Entomol Res, 96:91-98

Kato H, Xie G, Sato Y, Imai R (2010) Isolation of anther-specific gene promoters suitable for transgene expression in rice. Plant Mol Biol Rep 28:381-387.

Kawanabe T, Ariizumi T, Kawai-Yamada M, Uchimiya H, Toriyama K (2006) Abolition of the Tapetum Suicide Program Ruins Microsporogenesis. Plant Cell Physiol. 47: 784-787

Kerk NM, Ceserani T, Tausta SL, Sussex IM, Nelson TM (2003) Laser capture microdissection of cells from plant tissues. Plant Physiol 132:27-35

Koltunow AM, Truettner J, Cox KH, Wallroth M, Goldberg RB (1990) Different temporal and spatial gene expression patterns occur during anther development. Plant Cell 2: 12011224

Konagaya K, Ando S, Kamachi S, Tsuda M, Tabei Y (2008) Efficient production of genetically engineered, male-sterile Arabidopsis thaliana using anther-specific promoters and genes derived from Brassica oleracea and B. rapa. Plant Cell Rep 27:1741-1754

Lee S, Jung KH, An G, Chung YY (2004) Isolation and characterization of a rice cysteine protease gene, OsCP1, using T-DNA gene-trap system, Plant Mol. Biol. 54: 755-765. 
Li N, Zhang DS, Liu HS, Yin CS, Li XX, Liang WQ, Yuan Z, Xu B, Chu HW, Wang J, Wen TQ, Huang $\mathrm{H}$, Luo D, Ma H, Zhang DB (2006) The rice tapetum degeneration retardation gene is required for tapetum degradation and anther development. Plant Cell 18: 2999-3014.

Lowry O, Rosebrough NJ, Farr AL, Randall RJ (1951) Protein measurement with the folin-phenol reagent. J. Biol. Chem. 193: 265-275

Mariani C, Beuckeleer MD, Truettner J, Leemans J, Goldberg RB (1990) Induction of male sterility in plants by a chimeric ribonuclease gene, Nature 347: 737-741

Mariani C, Gossele V, Beuckeleer MD, Block MD, Goldberg RB, Greef WD, Leemans J (1992) A chimeric ribonuclease inhibitor gene restores fertility to male sterile plants. Nature 357 : 384-387

McNeil KJ, Smith AG (2005) An anther-specific cysteine-rich protein of tomato localized to the tapetum and microspores. J. Plant Physiol. 162: 457-464.

Meichtry J, Amrhein N, Schaller A (1999) Characterization of the subtilase gene family in tomato (Lycopersicon esculentum Mill). Plant Mol. Biol. 39: 749-760

Michaud D, Fayes I, Yells S (1993) Electrophoretic analysis of plant cysteine and serine proteinases using gelatin-containing polyacrylamide gels and class-specific proteinase inhibitors. Electrophoresis 14: 94-98

Murphy DJ, Ross JHE (1998) Biosynthesis, targeting and processing of oleosin-like proteins, which are major pollen coat components in Brassica napus. Plant J. 13: 1-16

Parish RW, Li SF (2010) Death of a tapetum: A programme of developmental altruism. Plant Sci 178: 73-89.

Perez-Prat E, Campagne MM (2002) Hybrid seed production and the challenge of propogating male sterile plants. Trends Plant Sci. 7: 199-203

Radlowski M, Kalinowski A, Adamczyk J, Krolikowski Z, Bartkowiak S (1996) Proteolytic activity in the maize pollen wall. Physiol. Plant 98: 172-178

Reeck RG, Kramer KJ, Baker JK, Kanost MR, Fabrick JA, Behnke CA (1997) Proteinase inhibitors and resistance of transgenic plants to insects. In: Corozzi N, Koziel M (eds.) Advances in Insect Control, Taylor and Francis, pp 157-179

Sambrook J, Fritsch EF, Maniatis T (1989) Molecular Cloning. A Laboratory Manual, Cold Spring Harbor

Sanders PM, Bui AQ, Weterings K, McIntire KN, Hsu Y, Lee PY, Truong MT, Beals TP, Goldberg RB (1999) Anther developmental defects in Arabidopsis thaliana male-sterile mutants. Sex Plant Reprod. 11: 297-322

Schaller A (2004) A cut above the rest: the regulatory function of plant proteinases. Planta 220: 183-197

Schiefthaler U, Balasubramanian S, Sieber P, Chevalier D, Wisman E, Schneitz K (1999) Molecular analysis of NOZZLE, a gene involved in pattern formation and early 
sporogenesis during sex organ development in Arabidopsis thaliana. Proc. Natl. Acad. Sci. U.S.A. 96: 11664-11669.

Scott R, Dagless E, Hodge R, Paul W, Soufleri I, Draper J (1991a) Patterns of gene expression in developing anthers of Brassica napus. Plant Mol. Biol. 17: 195-207

Scott R, Hodge R, Paul W, Draper J (1991b) The molecular biology of anther differentiation. Plant Sci 80:167-191

Sridhar VV (2001) Expression of heterologous genes T-urf13 and Fen in rice: Strategies for male sterility and disease resistance. Ph.D. Dissertation, University of Madras, Chennai.

Taylor AA, Horsch AP, Rzepczyk A, Hasenkampf CA, Riggs CD (1997) Maturation and secretion of a serine proteinase is associated with events of late microsporogenesis. Plant J. 12: 1261-1271

Vierstra RD (2003) The ubiquitin/26S proteasome pathway, the complex last chapter in the life of many plant proteins. Trends Plant Sci. 8: 135-142

Walden AR, Walter C, Gardner RC (1999) Genes expressed in Pinus radiate male cones include homologs to anther-specific and pathogenesis response genes. Plant Physiol. 121: 11031116 .

Wang H, Makeen K, Yan Y, Cao Y, Sun S, Xu G (2010) OsSIZ1 regulates the vegetative growth and reproductive development in rice. Plant Mol Biol Rep DOI 10.1007/s11105-010-0232-y

Wang M, Hoekstra S, van Bergen S, Lamers GEM, Oppedijk BJ, van der Heijden MW (1999) Apoptosis in developing anthers and the role of $A B A$ in this process during androgenesis in Hordeum vulgare L. Plant Mol. Biol. 39: 489-501

Weltering EJ (2010) Death proteases: Alive and kicking. Trends Plant Sci 15(4): 185-189.

Worrall D, Hird DL, Hodge R, Paul W, Draper J, Scott R (1992) Premature dissolution of the microsporocyte callose wall cause male sterility in transgenic tobacco. Plant cell 4: 759-771 Yang WC, Ye D, Xu J, Sundaresan V (1999) The SPOROCYTELESS gene of Arabidopsis is required for initiation of sporogenesis and encodes a novel nuclear protein. Genes Dev. 13: 2108-2117.

Zhang DS, Liang WQ, Yuan Z, Li N, Shi J, Wang J, Liu YM, Yu WJ, Zhang DB (2008) Tapetum Degeneration Retardation is Critical for Aliphatic Metabolism and Gene Regulation during Rice Pollen Development. Mol. Plant 1: 599-610

Zhang W, Sun Y, Timofejeva L, Chen C, Grossniklaus U, Ma H (2006) Regulation of Arabidopsis tapetum development and function by DYSFUNCTIONAL TAPETUM1 (DYT1) encoding a putative bHLH transcription factor. Development 133: 3085-3095.

Zhang Z, Zheng Y (2008) Identification of candidate genes associated with fertility restoration in maize S cytoplasmic male sterility. Plant Mol Biol Rep 26: 60-71. DOI 10.1007/s11105-0080023-x 
Zhang ZB, Zhu J, Gao JF, Wang C, Li H, Zhang HQ, Zhang S, Wang DM, Wang QX, Huang H, Xia HJ, Yang ZN (2007) Transcription factor AtMYB103 is required for anther development by regulating tapetum development, callose dissolution and exine formation in Arabidopsis. Plant J. 52: 528-538.

Zhao DZ, Wang GF, Speal B, Ma H (2002) The EXCESS MICROSPOROCYTES 1 gene encodes a putative leucine-rich repeat receptor protein kinase that controls somatic and reproductive cell fates in the Arabidopsis anther. Genes Dev. 16: 2021-2031. 
1 Table 1 Pollen production and percentage of pollen germination of transgenic plants 2

\begin{tabular}{|c|c|c|c|c|}
\hline Name of plant & Generation & $\begin{array}{c}\text { Average } \\
\text { number of } \\
\text { pollen per } \\
\text { anther }\end{array}$ & $\begin{array}{c}\text { Percentage of } \\
\text { pollen } \\
\text { germination }\end{array}$ & Remarks \\
\hline $\begin{array}{c}\text { C (untransformed Petit } \\
\text { havana) }\end{array}$ & $\mathrm{T}_{1}$ & $5 \times 10^{4}$ & $\begin{array}{c}85.3 \\
(3.568 / 2.060)\end{array}$ & $\begin{array}{l}\text { Fertile, normal pollen } \\
\text { Self pollination }\end{array}$ \\
\hline $\begin{array}{c}1229 n 10 \text { (vector } \\
\text { control) }\end{array}$ & $\mathrm{T}_{0}$ & $4.9 \times 10^{4}$ & $\begin{array}{c}88.3 \\
(1.994 / 1.151)\end{array}$ & $\begin{array}{l}\text { Fertile, normal pollen } \\
\text { Self pollination }\end{array}$ \\
\hline TA2-5 & $\mathrm{T}_{1}$ & $1 \times 10^{3}$ & $\begin{array}{c}25.8 \\
(5.220 / 3.014)\end{array}$ & $\begin{array}{l}\text { Semi-sterile, abnormal pollen, } \\
\text { manual pollination }\end{array}$ \\
\hline TA4 & $\mathrm{T}_{0}$ & $1.9 \times 10^{2}$ & $2.3(0.634 / 0.366)$ & $\begin{array}{l}\text { Sterile, shrunken pollen, } \\
\text { manual pollination }\end{array}$ \\
\hline TA12-2 & $\mathrm{T}_{1}$ & $2 \times 10^{3}$ & $\begin{array}{c}24.8 \\
(5.907 / 3.410)\end{array}$ & $\begin{array}{c}\text { Semi-sterile, abnormal pollen, } \\
\text { manual pollination }\end{array}$ \\
\hline TA20 & $\mathrm{T}_{0}$ & $2.1 \times 10^{2}$ & $9.4(3.847 / 2.221)$ & $\begin{array}{l}\text { Sterile, shrunken pollen, } \\
\text { manual pollination }\end{array}$ \\
\hline TA31-9 & $\mathrm{T}_{1}$ & $2.5 \times 10^{3}$ & $65(4.893 / 2.825)$ & $\begin{array}{c}\text { Semi-sterile, abnormal pollen, } \\
\text { manual pollination }\end{array}$ \\
\hline
\end{tabular}

\footnotetext{
3 Numbers in parenthesis in percentage of pollen germination are standard deviation (SD) and standard error

4 (SE) for each of the samples.

5

6 
Fig. 1 1a. Schematic representation of the construct p1229n (vector control) used in the present study. LB - left border, RB - right border, Hph - hygromycin phosphotransferase gene

1b. Integration Southern analysis of tobacco plants transformed with Aprotinin gene. The plasmid pTA and genomic DNA of plants were digested with HindlII and blotted onto $\mathrm{N}^{+}$nylon membrane. Most of the transgenic plants showed integration of Aprotinin gene into their genome. $\mathrm{kb}$ - kilo base, bp - base pair, LB - left border, RB - right border

Fig. 2 Morphology of control (untransformed Petit havana) and transgenic plants carrying Aprotinin gene. The transverse section of anther of the transgenic plant (TA12, c) was similar to untransformed tobacco anther (a) except for pollen production and damage in tapetum (red arrow heads). $\mathbf{b}$ and $\mathbf{d}$ represent magnified area of the tapetum of the control and transgenic plant respectively (red boxes of $\mathbf{a}$ and $\mathbf{c}$ )

Fig. 3 Floral morphology and seed production in $\mathrm{T}_{0}$ transgenic (TA4 and TA12 carrying Aprotinin gene) and untransformed tobacco plants (C) were compared; a The pollen production was reduced (red arrow heads) in the transgenic plants (TA4 and TA12) carrying Aprotinin gene but the flowers had a normal morphology; $\mathbf{b}$ The seed production was also reduced (red arrow heads) in these transgenic plants

Fig. 4 Pollen germination of transgenic plants carrying Aprotinin gene were compared with untransformed Petit havana (C) and 1229n 10 (vector control); a Pollen germination was markedly reduced in the transgenic plants expressing Aprotinin gene (TA2-5, TA12-2, TA4 and TA20); $\mathbf{b}$ The percentage of pollen germination in transgenic plants ranged from $65 \%$ in TA31-9 to $2.3 \%$ in TA4 transgenic plants expressing APROTININ whereas in transgenic plant carrying vector alone (p1229n) it was normal. Students ' $\mathrm{p}$ ' test was done for pollen germination data ( $\left.{ }^{*} \leq 0.001\right)$, standard deviation was also shown

Fig. 5 Zymogram analysis of total protein extracted from Stage 2 anthers of transgenic plants showing strong reduction in serine protease activity by APROTININ that was expressed in these plants (lanes 4-8). Proteinase (Trypsin) activity as clear zone (white arrow heads) was seen in lane 1, 2 while atleast three different serine proteinases can be seen in control plants that was transformed with vector (p1229n) (lane 3). kDa - kilo daltons 


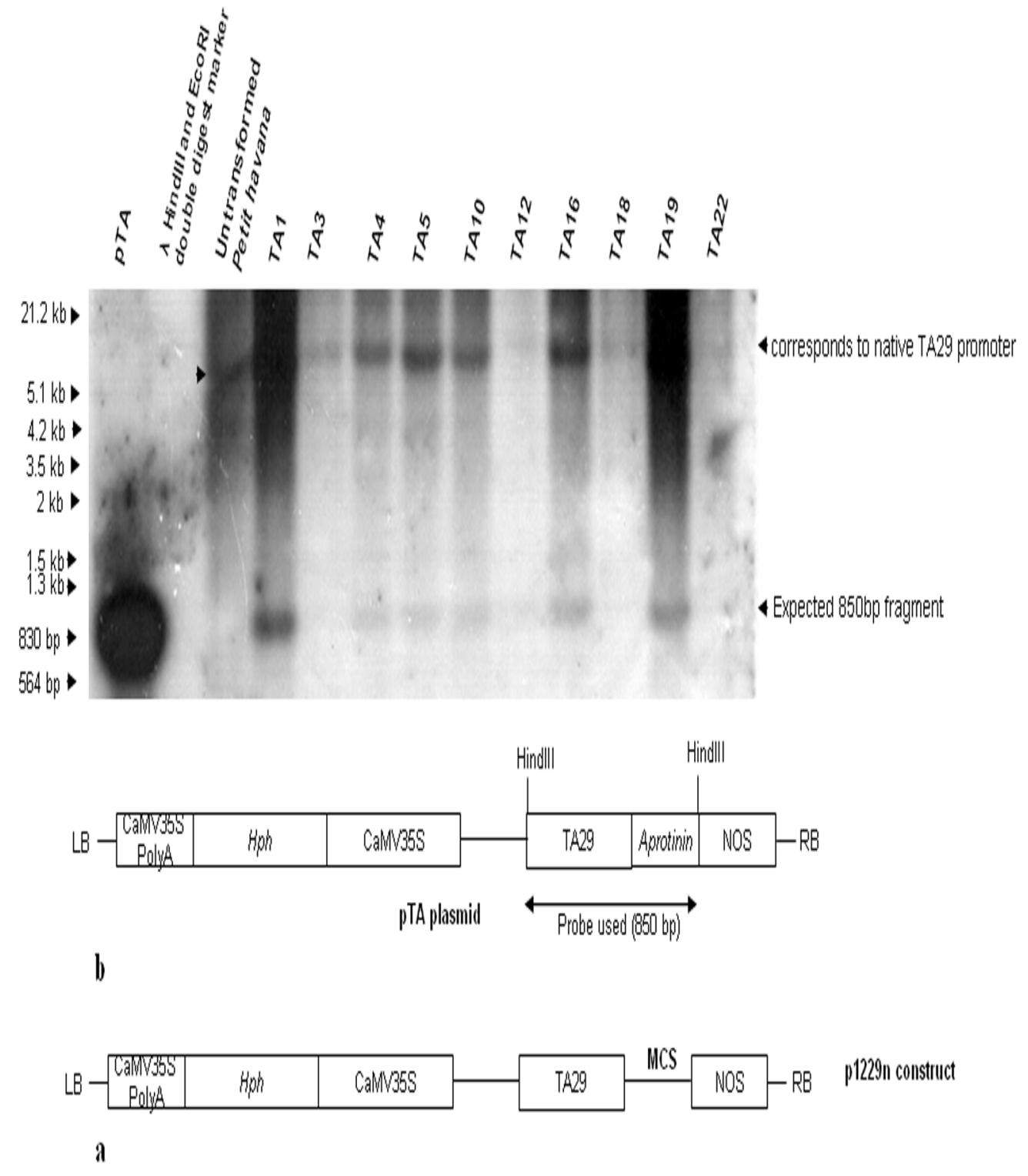

Fig. 1a. Schematicic representibtion of the constucut p1229n (vector controll).

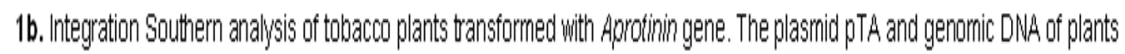
were digested with Hindlll and blotted onto Nt mylon membrorane. Most of the transgeric plants showed integration of Aprotining gene into their genome 


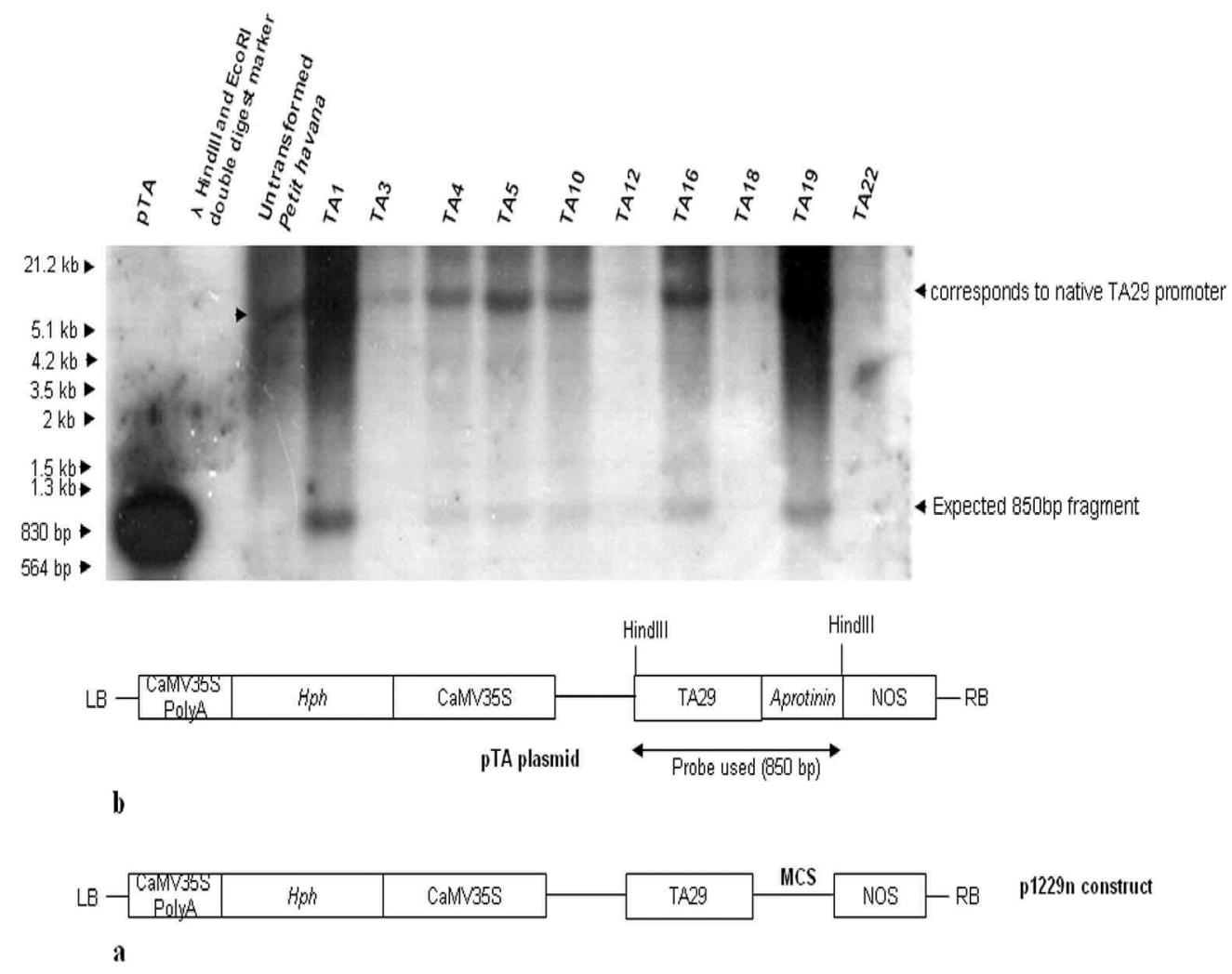

Fig. 1a. Schematic representation of the constuct p1229n (vector control).

1b. Integration Southern analysis of tobacco plants transformed with Aprotinin gene. The plasmid pTA and genomic DNA of plants were digested with Hind III and blotted onto $\mathrm{N}^{+}$nylon membrane. Most of the transgenic plants showed integration of Aprotiningene into their genome 


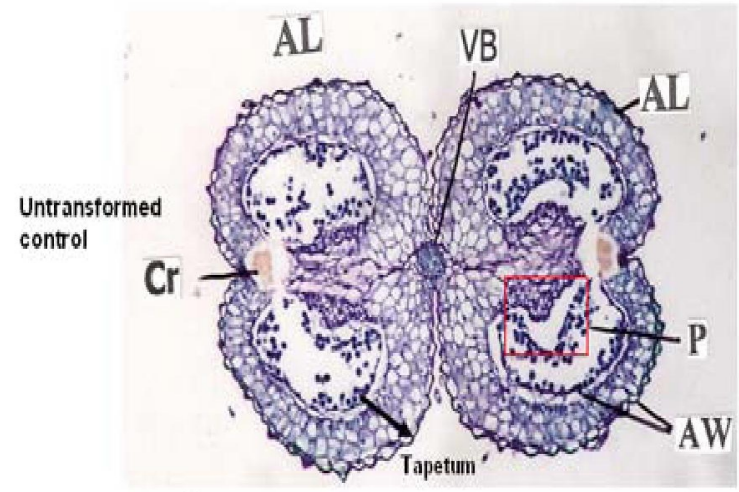

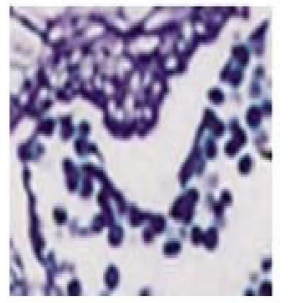

b

a

AL - Anther lobe, AW - Anther wall, Cr - Calcium oralate cystals, P - Pollen,

AL VB - Vacular Bunde, S-Stomium

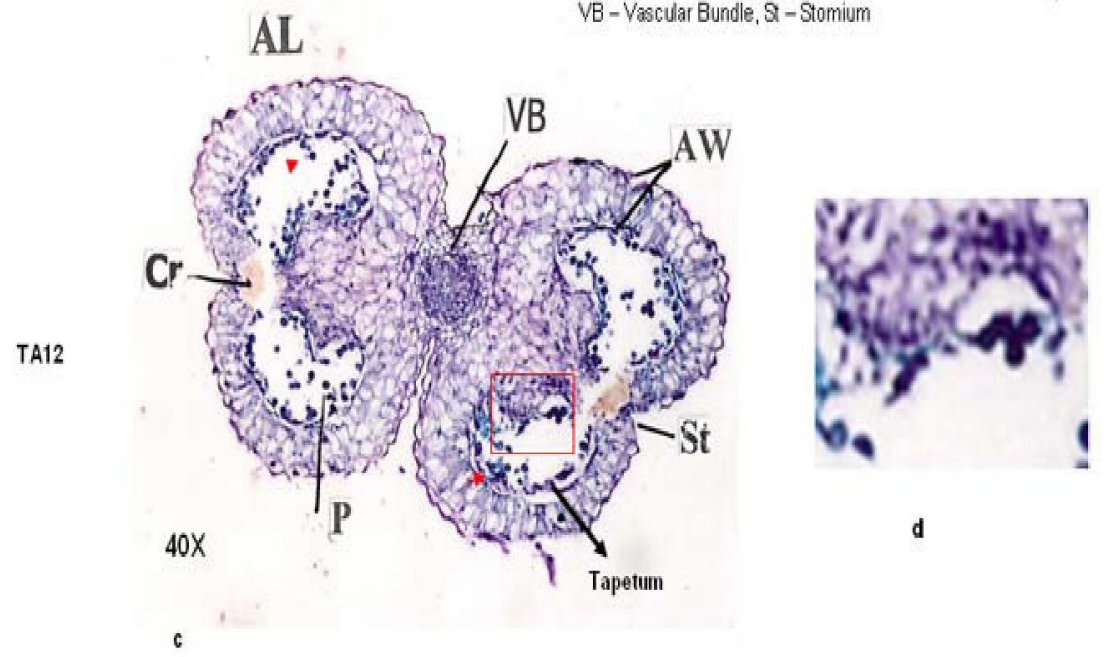

Fig. 2 Morphology of control (untranstormed Pett havana) and transgenic plants camying Aprotiningene. The transverse section of anther of the transgenic plant (TA12,c) was similar to untransformed tobacco anther (a) except for pollen production and darnage in tapetum (red arrow heads). $b$ and $\mathrm{d}$ represent rnagnified area of the tapeturn of the cortrol and transgenic plant respectively (red boxes of a and o) 


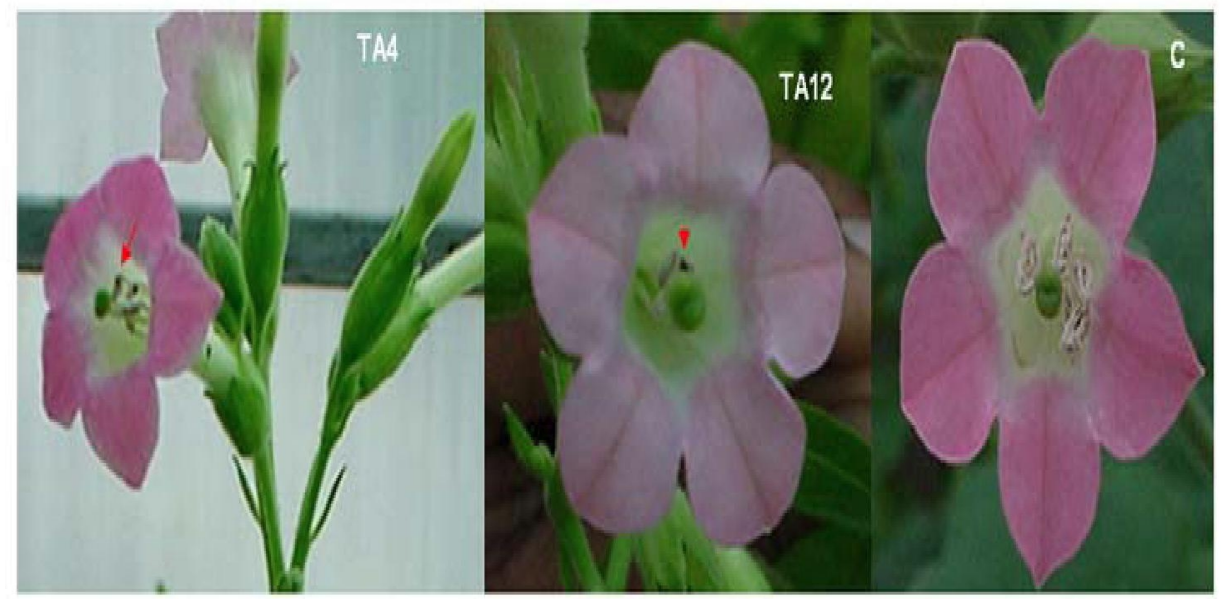

a

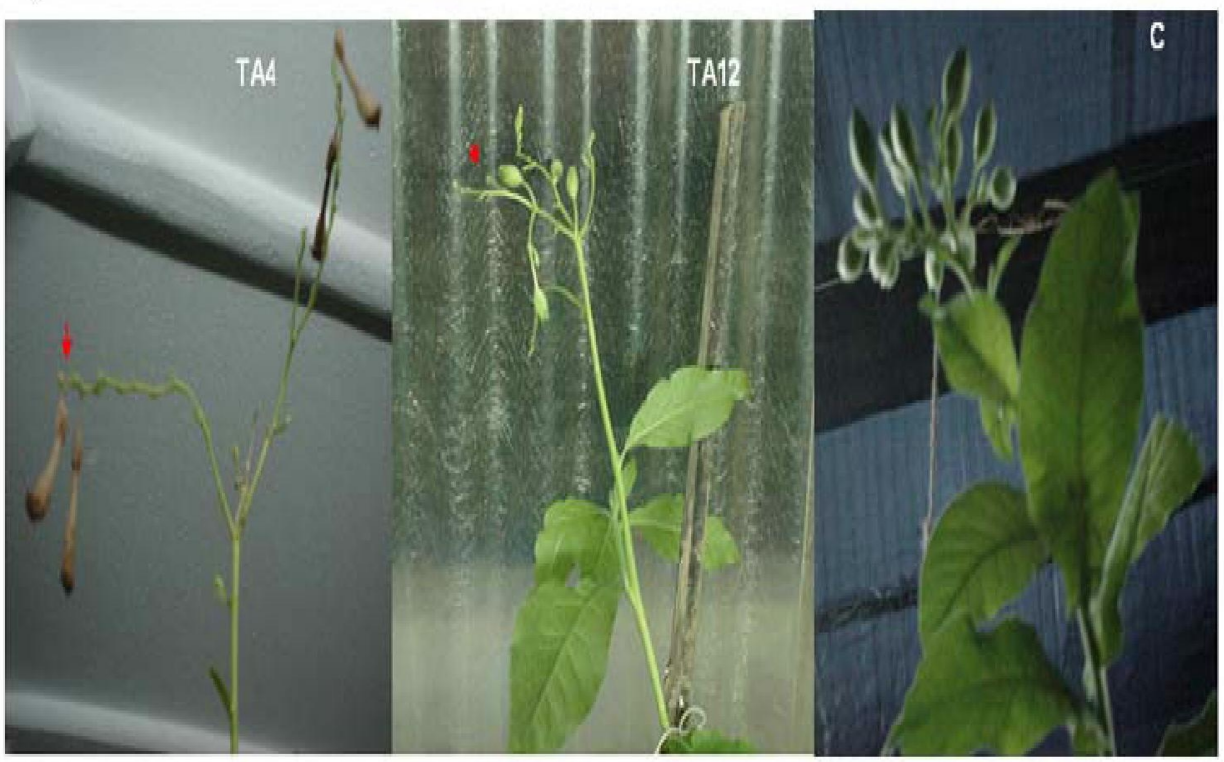

b

Fig. 3 Floral morphology and seed production in $T_{0}$ transgenic (TA4 and TA12 canying Aprdinin genè) and untransforméd tobacto plarts (C) are conparted. The pollen production was reduced (red arrow heads) in the transgenic plants (TA4 and TA12) camying Aorotiningene but the flowers had a nomal morphology (a), The seed production was also reduced (red arrow heads) in these transgenic plants (b) 


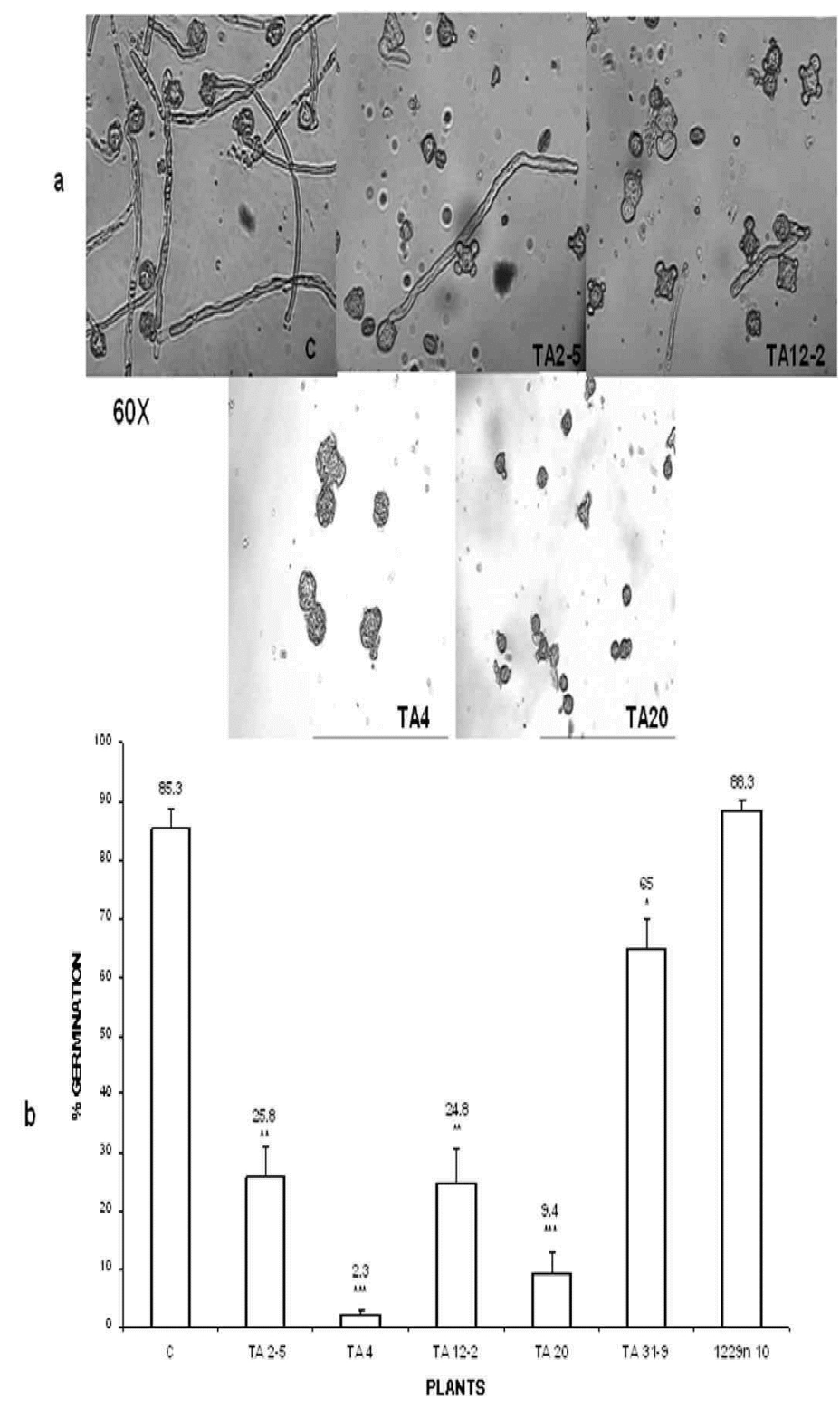

Fig. 4 Pollen germination of transgenic plants camying Aprotiningene were compared with untransformed Pefit havana (C) and $1229 n 10$ (vector control). Pollen germination was markedly reduced in the transgenic plarts expressing Aprotinin gene (TA2-5, TA12-2, TA4 and TA20) (a). The percentage of pollen germination in transgenic plants ranged from $65 \%$ in TA31-9 to $2.3 \%$ in TA4 transgenic plants expressing APROTINN (b) whereas in transgenic plart carnying vector alone ( $p 1229 n$ ) it was normal. Students t test was done for pollen germination data ( $\left.{ }^{*} P \leq 0.001\right)$, standard deviation was also shown 